\title{
Epidemiology of proximal and diaphyseal humeral fractures in children: an observational study from the Swedish Fracture Register
}

\author{
Sarah Daag Jacobsen ${ }^{*}$, Richard Marsell, Olof Wolf and Yasmin D. Hailer
}

\begin{abstract}
Background: Most fractures in children are fractures of the upper extremity. Proximal and diaphyseal humeral fractures account for a minority of these fractures. To our knowledge, few previous reports address these fractures. This study aimed to describe the epidemiology and current treatment of proximal and diaphyseal humeral fractures by using the Swedish Fracture Register (SFR).

Methods: In this nationwide observational study from the SFR we analysed data on patient characteristics, injury mechanism, fracture classification and treatment. We included patients aged $<16$ years at time of injury with proximal or diaphyseal humeral fracture registered in 2015-2019.

Results: 1996 (1696 proximal and 300 diaphyseal) fractures were registered. Proximal fractures were more frequent in girls whereas diaphyseal fractures were more frequent in boys. The median age at fracture was 10 years in both fracture types but patient's age was more widespread in diaphyseal fracture (IQR 5-13 compared to IQR 7-12 in proximal). In both sexes, the most registered injury mechanism was fall. Horse-riding was a common mechanism of injury in girls, whereas ice-skating and skiing were common mechanisms in boys. Most proximal fractures were metaphyseal fractures. Most diaphyseal fractures were simple transverse or oblique/spiral fractures. The majority of fractures were treated non-surgically (92\% of proximal and $80 \%$ of diaphyseal fractures). The treatment method was not associated with the patient's sex. Surgery was more often performed in adolescents. The most common surgical methods were K-wire and cerclage fixation in proximal fracture and intramedullary nailing in diaphyseal fracture.
\end{abstract}

Conclusion: Following falls, we found sex-specific sport activities to cause most proximal and diaphyseal paediatric fractures. Further studies on prophylactic efforts in these activities are needed to investigate whether these fractures are preventable. The majority of the fractures were treated non-surgically, although surgical treatment increased with increasing age in both sexes.

Trial registration: Not applicable. The present study is a register-based cohort study. No health care intervention had been undertaken.

Keywords: Epidemiology, Children, Humerus, Fracture, Treatment, Swedish fracture register

${ }^{*}$ Correspondence: sarah.daagjacobsen@gmail.com

Department of Surgical Sciences, Section of Orthopaedics, Uppsala

University, Uppsala, Sweden

\section{Background}

One in three children sustain a fracture during childhood and adolescence [1]. Previous studies report that almost $80 \%$ of these fractures are fractures of the upper extremity $[2,3]$ and that humeral fractures account for less than $10 \%$ of all fractures in children $[4,5]$. The majority $(70 \%)$ original author(s) and the source, provide a link to the Creative Commons licence, and indicate if changes were made. The images or other third party material in this article are included in the article's Creative Commons licence, unless indicated otherwise in a credit line to the material. If material is not included in the article's Creative Commons licence and your intended use is not permitted by statutory regulation or exceeds the permitted use, you will need to obtain permission directly from the copyright holder. To view a copy of this licence, visit http://creativecommons.org/licenses/by/4.0/. The Creative Commons Public Domain Dedication waiver (http://creativeco mmons.org/publicdomain/zero/1.0/) applies to the data made available in this article, unless otherwise stated in a credit line to the data. 
of these paediatric humeral fractures are supracondylar fractures [3-7]. Most research on humeral fractures in children therefore addresses only distal humeral fractures. Proximal and diaphyseal fractures subsequently remain relatively unexplored. Most studies on proximal and diaphyseal humeral fractures are either single-center studies with a retrospective design and relatively few patients included [8] or focus solely on different treatment techniques [9].

Paediatric fractures in general have a 1:1.5 ratio between girls and boys, and a unimodal age distribution with an observed incidence peak in early teenage years [1, $4,10]$. Most fractures are caused by falls or sport activities and the incidence of sport-related injuries increases with age $[4,10]$. Horse-related injuries are predominantly seen in girls and winter-related sports and transportation accidents in boys $[4,7,11,12]$. It is unclear if this pattern applies to proximal and diaphyseal humeral fractures as well.

There are some population-based studies of fractures in the Scandinavian paediatric population $[3,4,7,11]$. But to our knowledge, there is no published nationwide epidemiological study addressing humeral fractures other than distal fractures in a Scandinavian paediatric population.

This nationwide population-based observational study of proximal and diaphyseal humeral fractures in children and adolescents aims to describe the epidemiology of these fractures and possible associations between sex, age and the used treatment method. In addition, we aim to identify activities with high risk of injuries in the paediatric population, which in turn affects the patient inflow on orthopaedic care units as well as health economy.

Main hypotheses were that (i) proximal and diaphyseal humeral fractures are more common in boys, (ii) most injuries occur during recreational activities and (iii) that the incidence of surgical treatment increases with age. We hypothesised an increase in surgery with age due to the decrease in remodelling capacity with closed growth plates $[13,14]$.

\section{Methods}

\section{Data collection and study population}

This nationwide population-based observational study was conducted using the Swedish Fracture Register (SFR). The SFR is a national quality register compiling data on patient characteristics, injury mechanism, fracture classification and treatment. The treating physician is responsible for registration including classification of the fracture. The register was established in 2011 and since May 2015 the register has expanded to include also paediatric fractures [15]. Since 2021 all orthopaedic departments in Sweden report to the SFR $(100 \%$ coverage). Comparing the registered paediatric humeral fractures in the SFR with the National Patient Register, the completeness was $>70 \%$ in half of the affiliated hospitals and varying between 10 and $70 \%$ in the remaining hospitals. Most of the latter only registered surgically treated fractures (internal audit, data not published).

All patients < 16years of age at the time of injury, with a proximal or diaphyseal humeral fracture registered between 1 January 2015 and 31 December 2019, were included (8052 fractures). Supracondylar humeral fractures (6056 fractures) were excluded. Patients with two fractures (127 patients) registered within the time of study (either patients with multiple fractures and/or refractures) remained in the study.

\section{Variables}

Variables of interest included: patient's age, sex, injury date and injury mechanism. Furthermore, anatomical fracture classification and treatment method were assessed.

The mechanism of injury was divided into eight groups: simple falls, falls from height, unspecified falls, transportation accidents, stress/pathological/spontaneous fractures, non-accidental, other accidents and no mechanism registered (missing data). "Simple fall" included all falls in the same level (trips, in snow/ice, ice-skating/skiing, nudges) and "fall from height" all falls from another level (from furniture, playground facilities, stairs, trees, buildings). "Unspecified falls" were injuries registered as falls without information about which level they occurred in. "Transportation accidents" were divided into several subgroups; pedestrian, bicycle/motorcycle (including other small vehicles), car (including truck), horse-riding and unspecified transportation accidents. "Non-accidental injuries" were all injuries due to fights, abuse and selfdestructive acts. "Other accidents" were injuries due to mechanical and living forces.

The fractures were categorized according to the paediatric AO/OTA classification system (Figs. 1 and 2). The fractures were also divided into groups of adult patients with closed growth plates or paediatric patients with open growth plates. In proximal fractures, fractures categorized as Salter-Harris III, IV, and intraarticular fragments were all categorized as "intraarticular fractures".

Treatment was divided into two main categories; non-surgical and surgical treatment. The surgical treatment category also included those patients which had a change of their treatment regime from initial nonsurgical treatment to surgical within 2 weeks of the injury. The non-surgical group was further divided into a non-surgical or non-surgical with closed reduction group, and the surgical group to; a) closed reduction under general anaesthesia, b) k-wire and cerclage, c) 


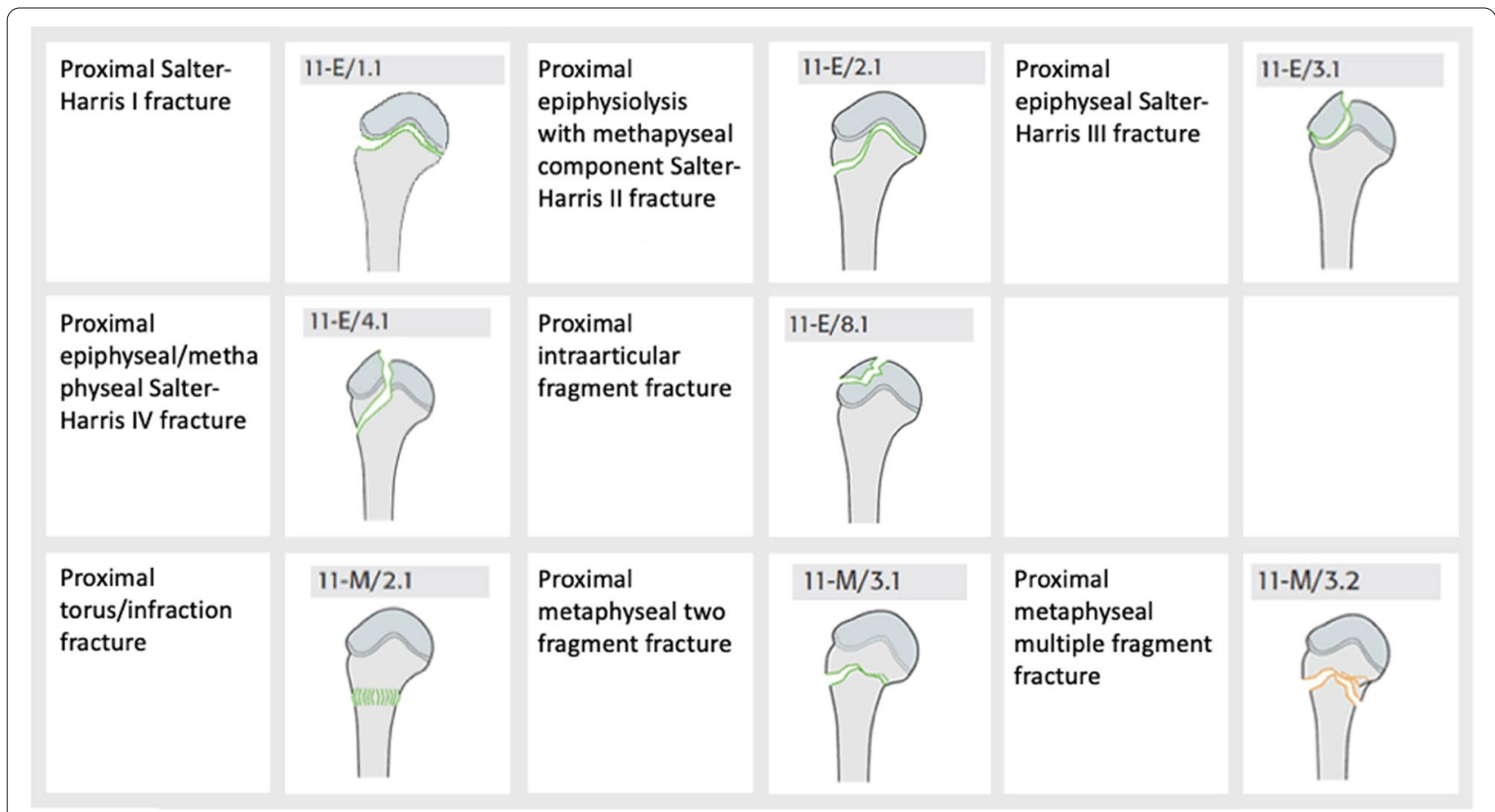

Fig. 1 Fracture classification according to the AO/OTA classification system. From the Swedish Fracture Register

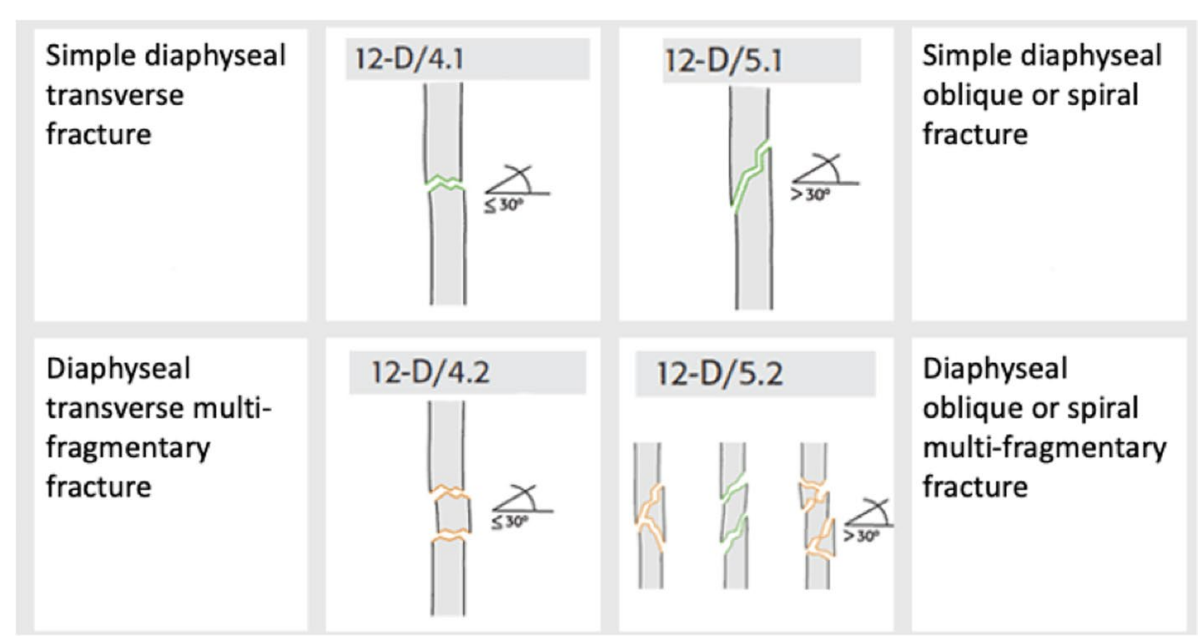

Fig. 2 Fracture classification according to the AO/OTA classification system. From the Swedish Fracture Register

intramedullary nailing (including both rigid and flexible nails), d) plate fixation, e) screw fixation, f) combined osteosynthesis and g) external fixation groups. The chosen method of treatment was then surveyed in four different age groups; infancy and toddlerhood ( $0-3$ years), preschool ( $4-6$ years), school-age ( $7-12$ years) and adolescence (13-15 years).

\section{Statistics}

The statistical analyses were performed using Excel (Microsoft Excel for Mac version 16.31, Microsoft Corporation, Redmond, WA) and R version 3.6.3 (February 29, 2020). Descriptive statistics (counts, median with interquartile range and percentage) were used to describe the collected data. Logistic regression was performed to 
estimate the odds ratio (OR). Statistical significance was defined as $p<0.05$.

\section{Results}

1696 (21\%) of all registered humeral fractures (8052) were proximal fractures, and $300(4 \%)$ were diaphyseal. There were 5 open fractures, $1(0.01 \%)$ in girls and 4 in boys $(0.2 \%)$ (Table 1$)$. Two patients (both boys) died within the study period. No data on their date or cause of death was available.

\section{Patient characteristics}

The total girl:boy-ratio was $1.5: 1$ in proximal fractures and 1:1.9 in diaphyseal. The proximal to diaphyseal fracture ratio was 9.7:1 in girls and 3.5:1 in boys. In proximal

Table 1 Basic characteristics of all fractures

\begin{tabular}{llll}
\hline & Proximal & Diaphyseal & Total \\
\hline $\begin{array}{llll}\text { Sex } \\
\text { Girls, } n(\%)\end{array}$ & $1004(59)$ & $103(34)$ & $1107(55)$ \\
Boys, $n(\%)$ & $692(41)$ & $197(66)$ & $889(45)$ \\
$\quad$ Total, n (\%) & $1696(100)$ & $300(100)$ & $1996(100)$ \\
Median age (IQR) & & & \\
Girls & $10(7-12)$ & $9(5-12)$ & $10(7-12)$ \\
Boys & $11(8-13)$ & $10(6-13)$ & $11(7-13)$ \\
Total & $10(7-12)$ & $10(5-13)$ & $11(9-13)$ \\
Open fractures & & & $1(0.01)$ \\
Girls, n (\%) & 0 & 1 & $4(0.2)$ \\
Boys, n (\%) & 2 & 2 & $5(0.3)$ \\
Total, n (\%) & $2(0.1)$ & $3(1)$ & \\
\hline
\end{tabular}

fractures the age distribution was unimodal with a peak at 11 years in girls and a peak at 12 years in boys (Fig. 3 ). In diaphyseal fractures the age distribution was uneven (Fig. 4).

Regarding the proportion between proximal and diaphyseal humeral fractures by age group, patients between 0 and 3 years had the highest percentage of diaphyseal fractures (Fig. 5).

\section{Seasonal variation and injury mechanism}

Among girls, most fractures (124, 11\%) were registered in May (Fig. 6). The dominating mechanisms of injury for these fractures were falls at playground facilities (28, $23 \%)$ and due to horse-riding (17, 14\%). Among boys, most fractures $(94,11 \%)$ were registered in January. The dominating injury mechanism for these fractures were fall in the same level on snow/ice $(19,20 \%)$ or due to winter sport activities $(19,20 \%)$.

The overall dominating injury mechanism irrespective of the season were falls in both sexes. Injury details of the injury mechanisms are shown in Table 2.

Among girls, most transportation accidents were caused by horse-riding. Among boys, most transportation accidents were caused by riding a bike or moped.

\section{Fracture classification}

1696 (96\%) of all proximal fractures were classified as paediatric fractures (open growth plates) and the majority of those were located in the metaphysis (Fig. 7). There was no difference in fracture type between girls and boys. Only $30(3 \%)$ of the proximal fractures in girls and $22(3 \%)$ in boys were classified as

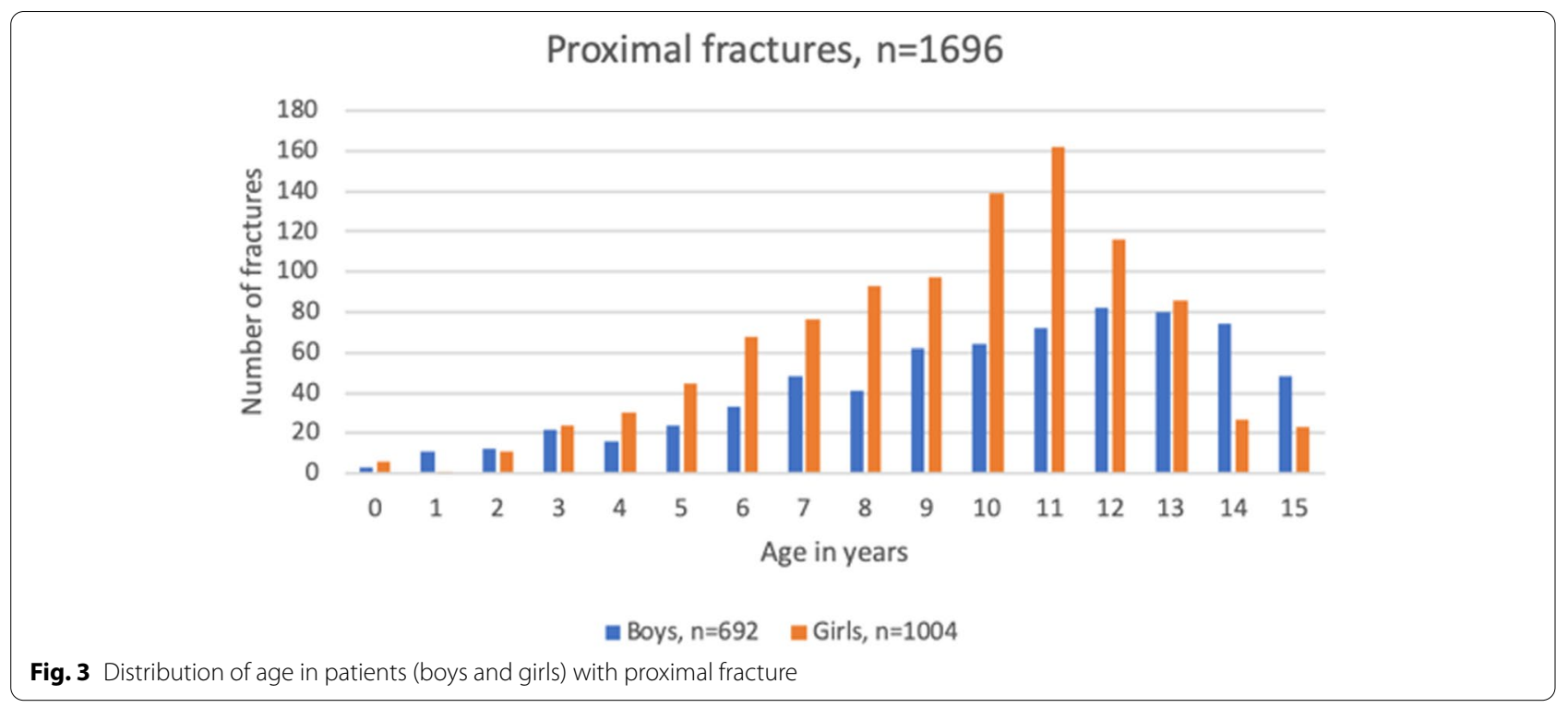




\section{Diaphyseal fractures, $n=300$}

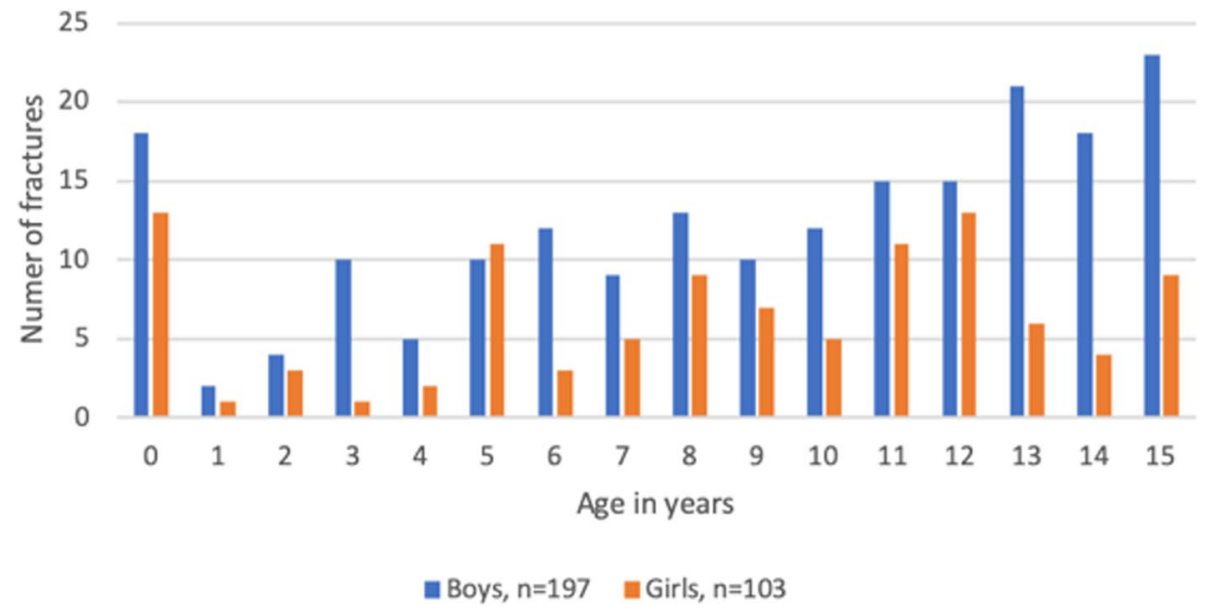

Fig. 4 Distribution of age in patients (boys and girls) with diaphyseal fracture

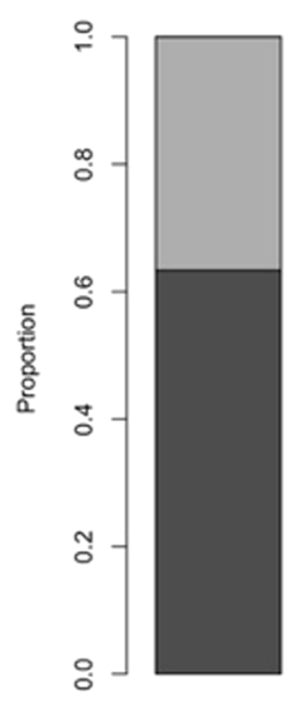

$0-3$

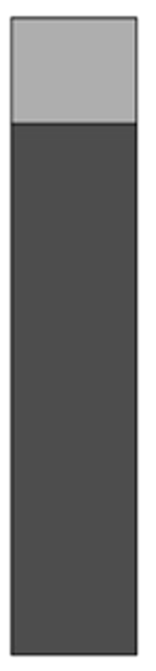

$4 \cdot 6$

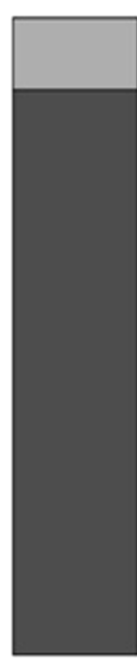

$7-9$

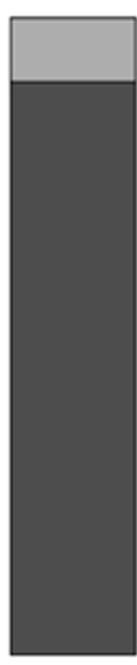

$10-12$

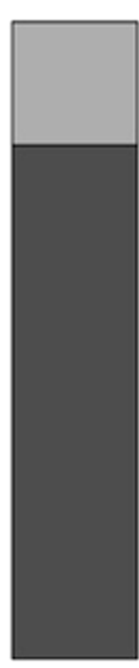

$13-15$

Age group

Fig. 5 Proportion of fracture (proximal or diaphyseal) location by age group

adult fractures (closed growth plates). In 15 fractures $(0.3 \%)$ information about the growth plate status was missing.

$300(88 \%)$ of diaphyseal fractures were classified as paediatric fractures (open growth plate) and the majority of those were simple transverse or oblique/spiral (Fig. 8). There was no difference in boys and girls. Of the diaphyseal fractures in girls, $15(15 \%)$ had closed growth plates and were therefore classified as adult fractures. This proportion was somewhat higher than in boys (8\%). In 6 cases $(0.2 \%)$ information about the growth plate status was missing.

\section{Treatment}

The majority of proximal $(1561,92 \%)$ and diaphyseal $(241,80 \%)$ humeral fractures were treated non-surgically. Logistic regression analysis revealed increased surgical intervention with increasing age in both locations. There was no significant difference in odds for surgical treatment between the sexes, see Table 3 . 


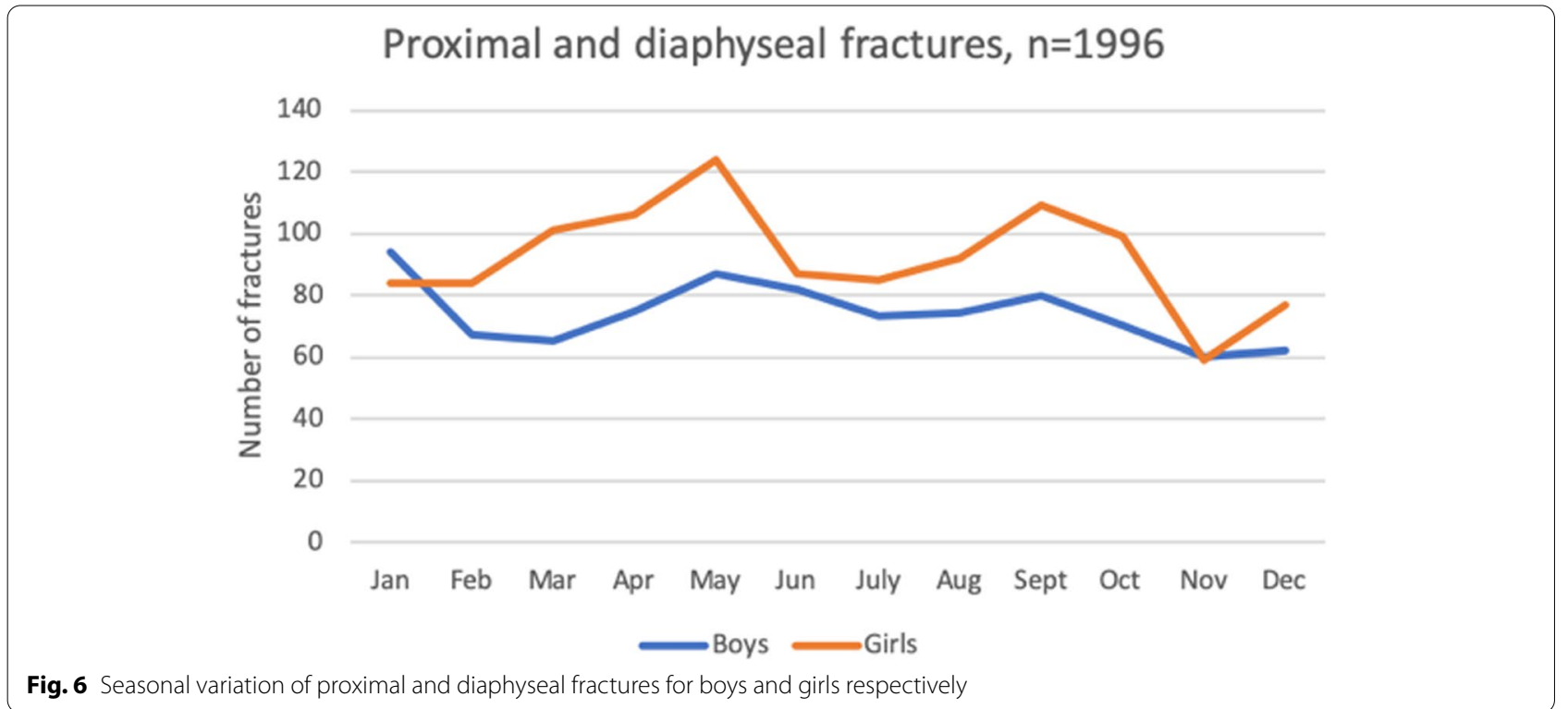

Table 2 Injury mechanism for proximal and diaphyseal humeral fractures presented for girls, boys and total

\begin{tabular}{|c|c|c|c|c|c|c|}
\hline & \multicolumn{3}{|l|}{ Proximal } & \multicolumn{3}{|l|}{ Diaphyseal } \\
\hline & Girls, n (\%) & Boys, n (\%) & Total, n (\%) & Girls, n (\%) & Boys, n (\%) & Total, n (\%) \\
\hline Simple falls & $287(29)$ & $258(37)$ & $545(32)$ & $19(18)$ & $56(28)$ & $75(25)$ \\
\hline Tripping & 149 & 127 & 275 & 11 & 30 & 41 \\
\hline Ice-skating/skiing & 70 & 65 & 135 & 5 & 14 & 19 \\
\hline On snow/ice & 42 & 40 & 82 & 2 & 9 & 11 \\
\hline Falls from height & $347(35)$ & $206(30)$ & $553(33)$ & $28(27)$ & $46(23)$ & $74(25)$ \\
\hline Playground facilites & 169 & 115 & 284 & 19 & 26 & 45 \\
\hline Unspecified falls & $78(8)$ & $34(5)$ & $112(7)$ & $3(3)$ & $10(5)$ & $13(4)$ \\
\hline Transportation accidents & $204(20)$ & $118(17)$ & $322(19)$ & $24(23)$ & $25(13)$ & $49(16)$ \\
\hline Pedastrian & 2 & 1 & 3 & 1 & 2 & 3 \\
\hline Bicycle/motorcycle & 43 & 106 & 149 & 8 & 19 & 27 \\
\hline Car & 1 & 1 & 2 & 1 & 3 & 4 \\
\hline Horse-riding & 150 & 5 & 155 & 13 & 1 & 14 \\
\hline Unspecified & 8 & 5 & 13 & 1 & 0 & 1 \\
\hline Stress/pathological/spontaneous & $2(0.2)$ & $2(0.3)$ & $4(0.2)$ & $2(2)$ & $14(7)$ & $16(5)$ \\
\hline Non-accidental & $3(0.3)$ & $3(0.4)$ & $6(0.4)$ & $3(3)$ & $4(2)$ & $7(2)$ \\
\hline Other accidents & $60(6)$ & $50(7)$ & $110(6)$ & $17(17)$ & $36(18)$ & $53(18)$ \\
\hline Not registered & $23(2)$ & $21(3)$ & $44(3)$ & $7(7)$ & $6(3)$ & $13(4)$ \\
\hline Total & $1004(100)$ & $692(100)$ & $1696(100)$ & $103(100)$ & $197(100)$ & $300(100)$ \\
\hline
\end{tabular}

In proximal fractures, the age at surgery was significantly lower among girls than boys ( 11 versus 12 years, $p<0.02)$. This was not the case in diaphyseal fracture (Figs. 9 and 10). 3 patients with proximal fractures and null patients with diaphyseal fracture had a registered reoperation.
99 proximal fractures were treated surgically. The preferred method in these fractures were K-wire and cerclage (65, 66\%). 46 diaphyseal fractures were treated surgically. The preferred method in these fractures were intramedullary nailing $(27,59 \%)$. For all proximal and diaphyseal fractures, flexible nails were used in 46 (92\%) 


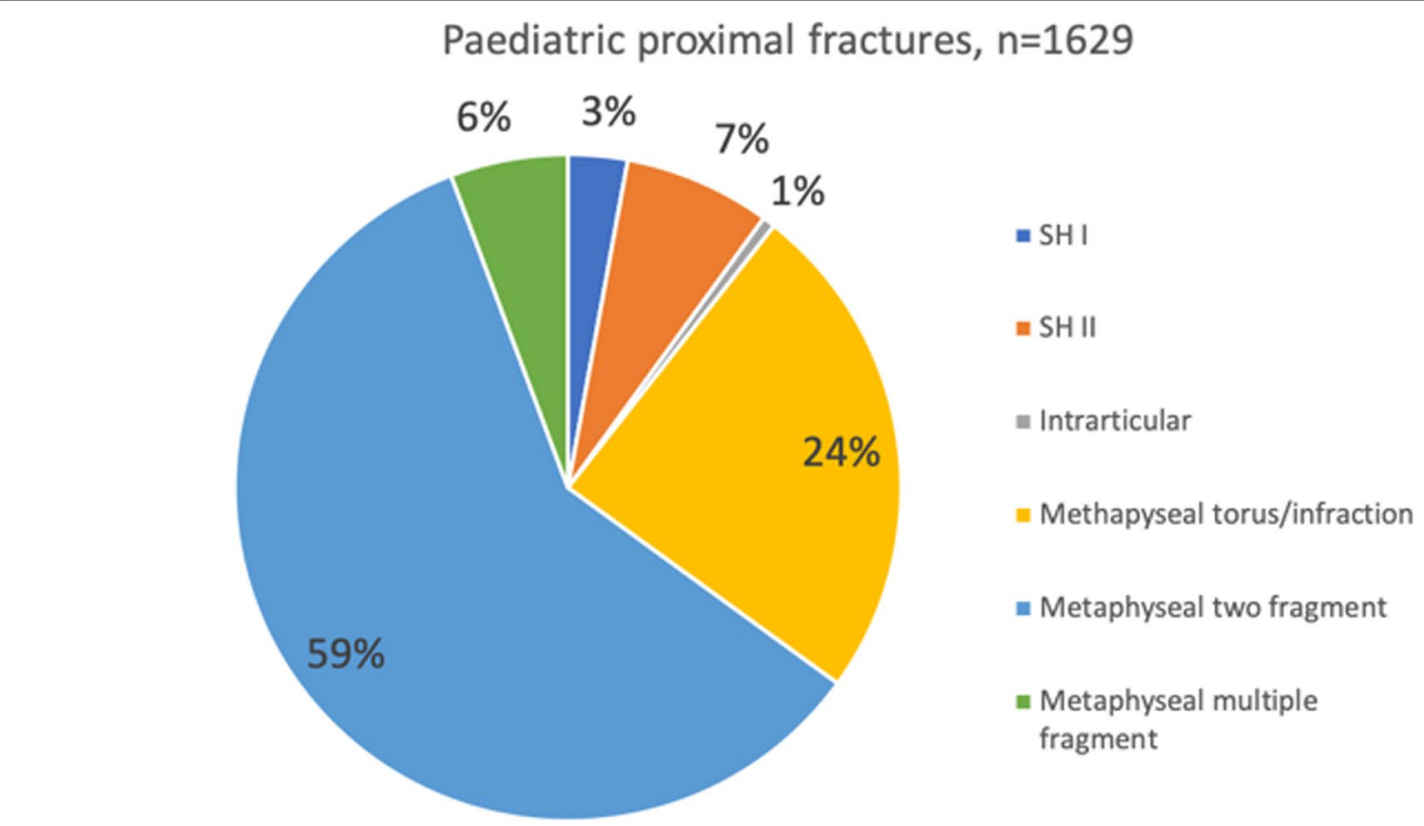

Fig. 7 Fracture classification in paediatric proximal fractures according to AO/OTA classification

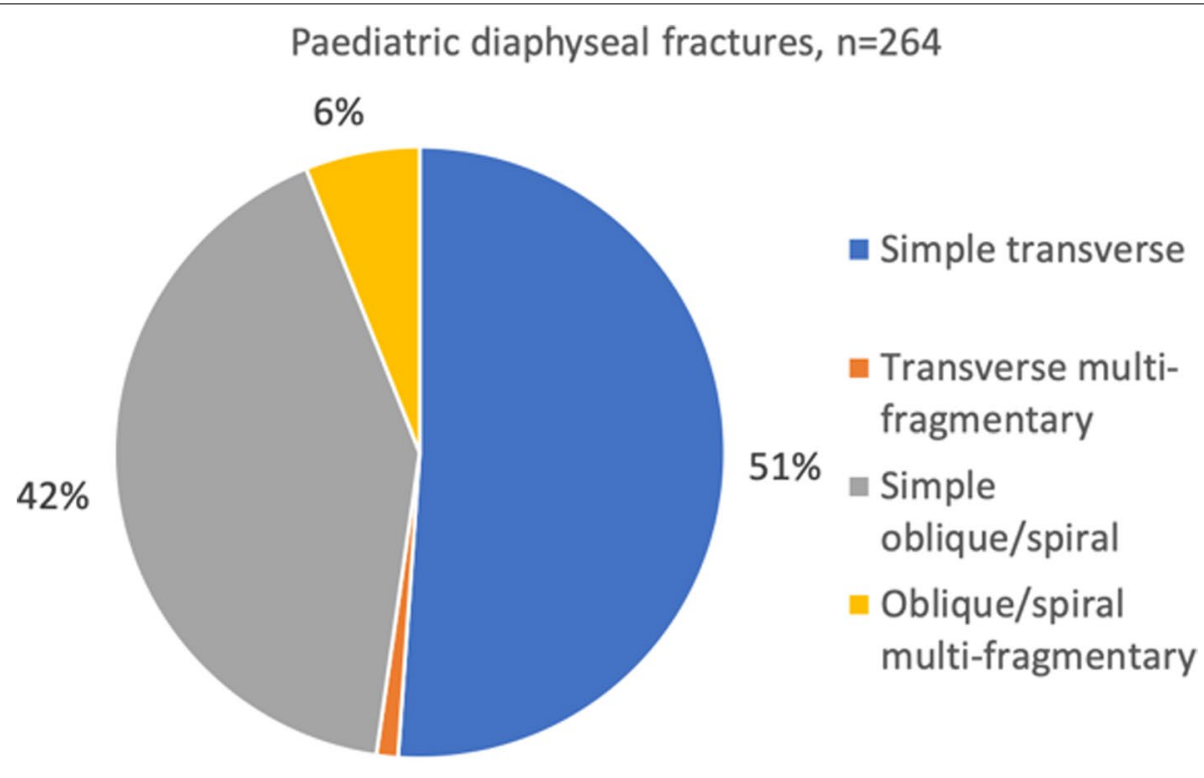

$1 \%$

Fig. 8 Fracture classification in paediatric diaphyseal fractures according to AO/OTA classification

of all 50 intramedullary nailing procedures (Tables 4 and $5)$.

\section{Discussion}

\section{Main findings}

$21 \%$ of all humeral fractures were proximal and $4 \%$ were diaphyseal. Girls were overrepresented in patients with proximal fractures and boys in diaphyseal fractures. Surgical treatment methods increased with increasing age, but they were not associated with sex.

\section{Fracture epidemiology}

As previous studies on general paediatric fracture epidemiology have reported a predominance in boys, we 
Table 3 Odds ratios for surgical treatment in relation to age at injury and sex

\begin{tabular}{llll}
\hline Proximal humerus fracture & OR & $\mathbf{9 5 \%}$ Confidence intervall & $\boldsymbol{P}$-value \\
\hline Age at fracture & 1.3 & & $1.2-1.4<0.001$ \\
$\begin{array}{l}\text { Sex (girl) } \\
\text { Diaphyseal humerus } \\
\text { fracture }\end{array}$ & 0.9 & $0.6-1.4$ & 0.7 \\
Age at fracture & $\mathbf{9 5 \%}$ Confidence intervall & $\boldsymbol{P}$-value \\
Sex (girl) & 1.2 & $1.1-1.3$ & $<0.001$ \\
\hline
\end{tabular}

hypothesised that most humeral fractures would occur in boys. As opposed to this, we found that most fractures occurred in girls. This due to the female dominance in proximal fractures. Previous studies have reported a girl:boy ratio of 1.4:1 [12], 1.8:1 [16] and 9.5:1 [11] in proximal fractures. Proximal humeral fractures are one of few paediatric fractures mainly afflicting girls and might be explained by the female predominance in horse-riding [12]. These findings are in line with our findings with a majority of proximal fractures in girls being caused by horse-riding. Data from The Swedish Research Council for Sport Science show that $96 \%$ of all children participating in horse-riding are girls. On the contrary, $94 \%$ of all participating in ice-hockey are boys [17]. This sexspecific difference in sporting activities can explain the female peak incidence in May and male peak incidence in January. Our results on seasonal variation and mechanism of injury confirms the hypothesis that most children sustain their fracture during recreational activities.

The unimodal age distribution in proximal fractures with an earlier incidence peak in girls than boys was in line with other nationwide studies of paediatric fracture epidemiology $[1,7,10]$. The earlier peak in injuries amongst girls compared to boys could be explained by

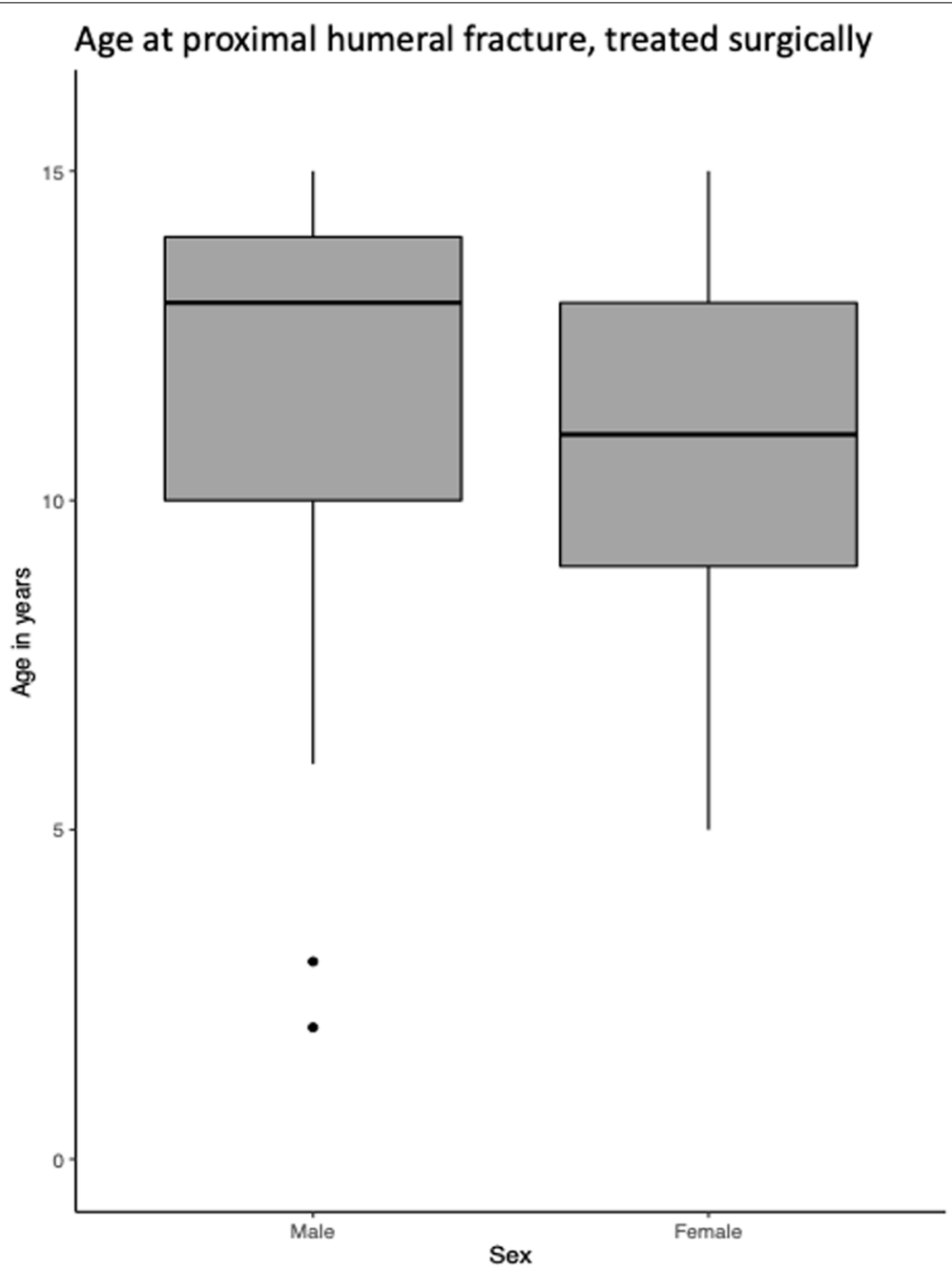

Fig. 9 Age at surgical treated proximal humeral fracture 


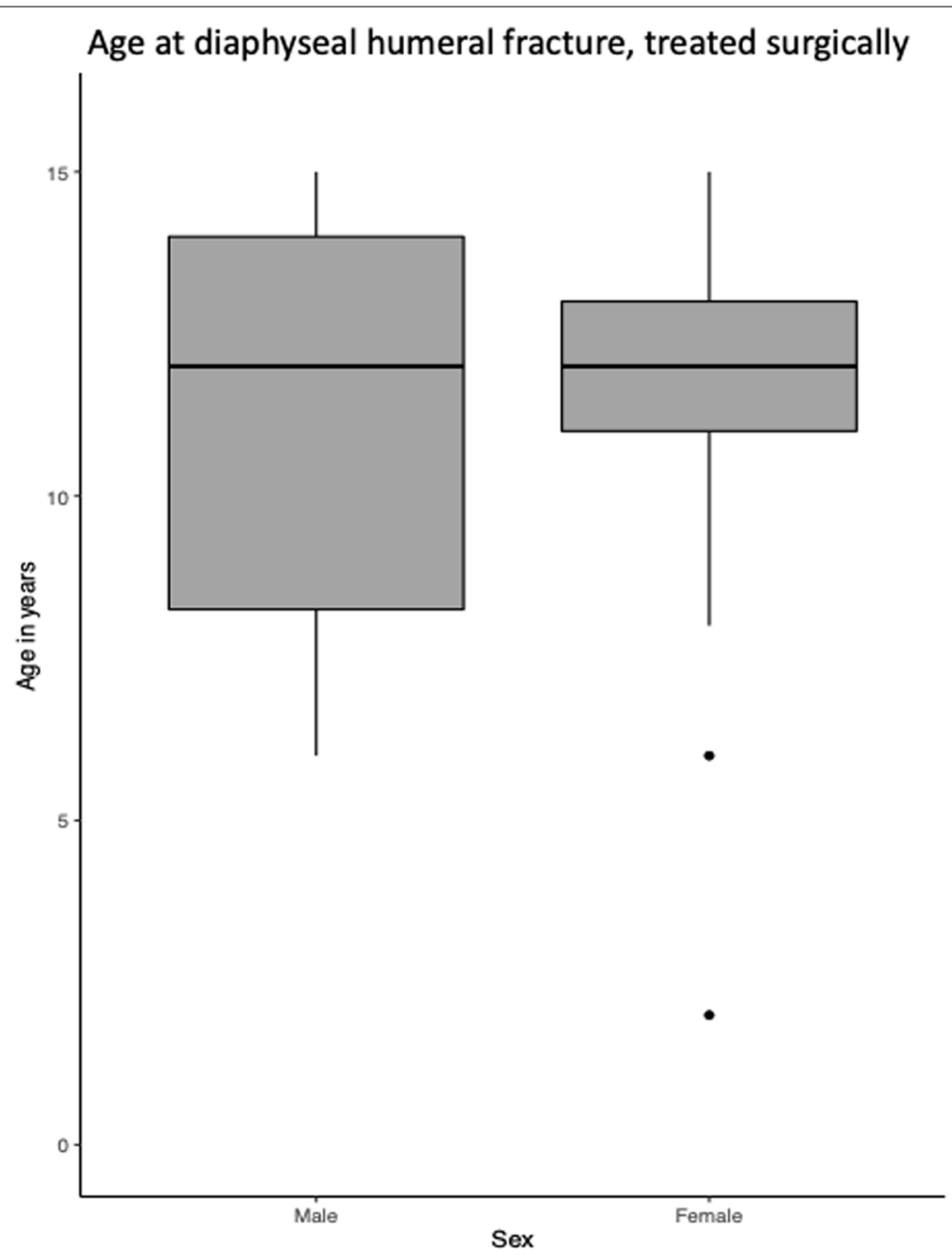

Fig. 10 Age at surgical treated diaphyseal humeral fracture

earlier puberty and growth spurt which causes a decrease in bone mineral density, making pubertal children more vulnerable to fractures [18]. In addition, our peak occurrences in diaphyseal fractures among infants and adolescents were also in line with other studies $[5,19]$. The high incidence amongst infants can be explained by birthrelated traumas, while traffic-related fractures might explain the increase in adolescents which is comparable with the cause of humeral fractures in adults [20].

\section{Fracture classification}

To our knowledge, this is the first study that analysed the anatomical fracture classification in paediatric proximal and diaphyseal humeral fractures. Only few paediatric humeral fractures are multi-fragmentary fractures which is in contrast with the reports of adult fractures. Bergdahl et al. reported in 2016 that $55 \%$ of all proximal and $16 \%$ of all diaphyseal fractures are multi-fragmentary fractures in adults [20]. This could be explained by the biomechanical properties of paediatric bone and the occurrence of a growth plate in the affected area [21]. In adults the relation to osteoporosis and lower bone mineral density could explain their vulnerability to multi-fragmentary fractures $[20,22]$.

\section{Treatment}

As previously described [23, 24], the most common treatment for humeral fractures was non-surgical treatment. In a Finnish study on proximal fractures, $8 \%$ were treated surgically [12] which corresponds well with our findings (7\% in boys and $5 \%$ in girls). In another Finnish study on diaphyseal fractures, $50 \%$ of all hospitalised children required surgery and/or fracture reduction [19]. In our population $20 \%$ of all patients with diaphyseal fractures 


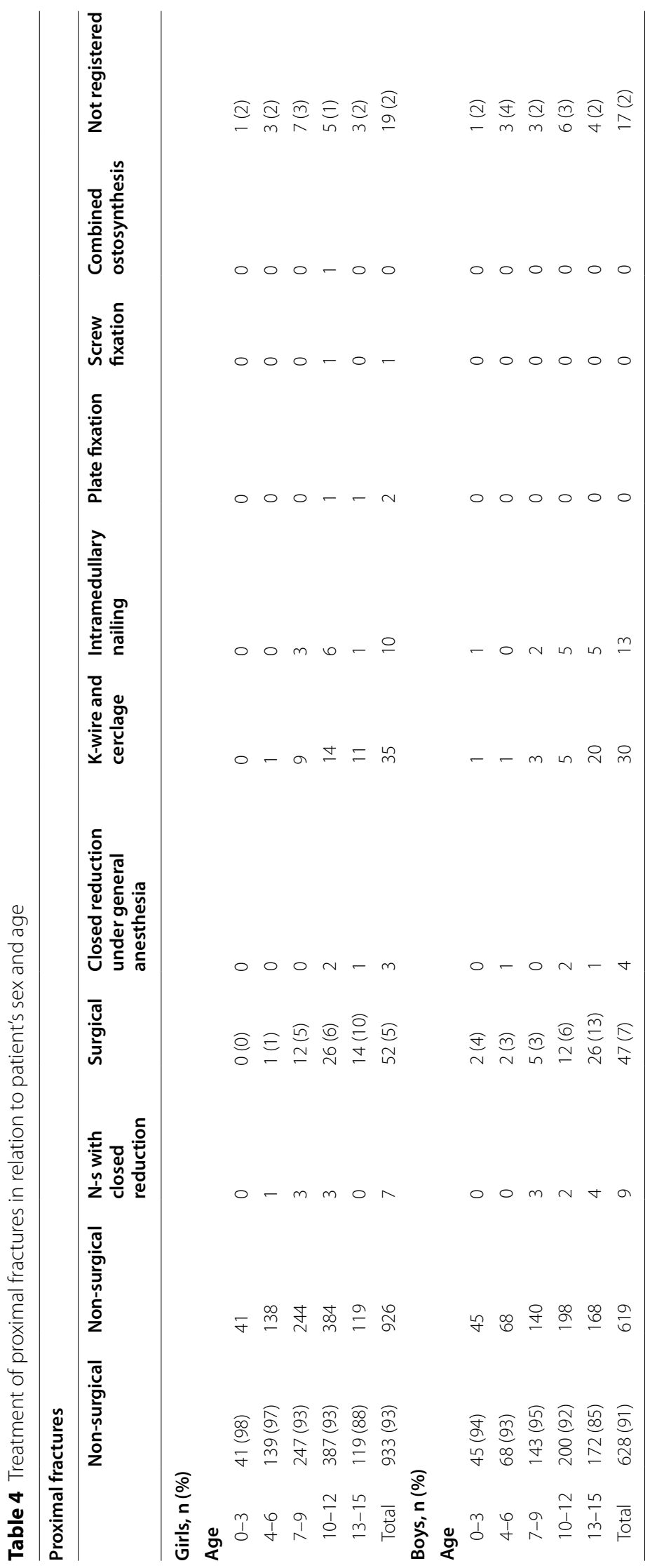




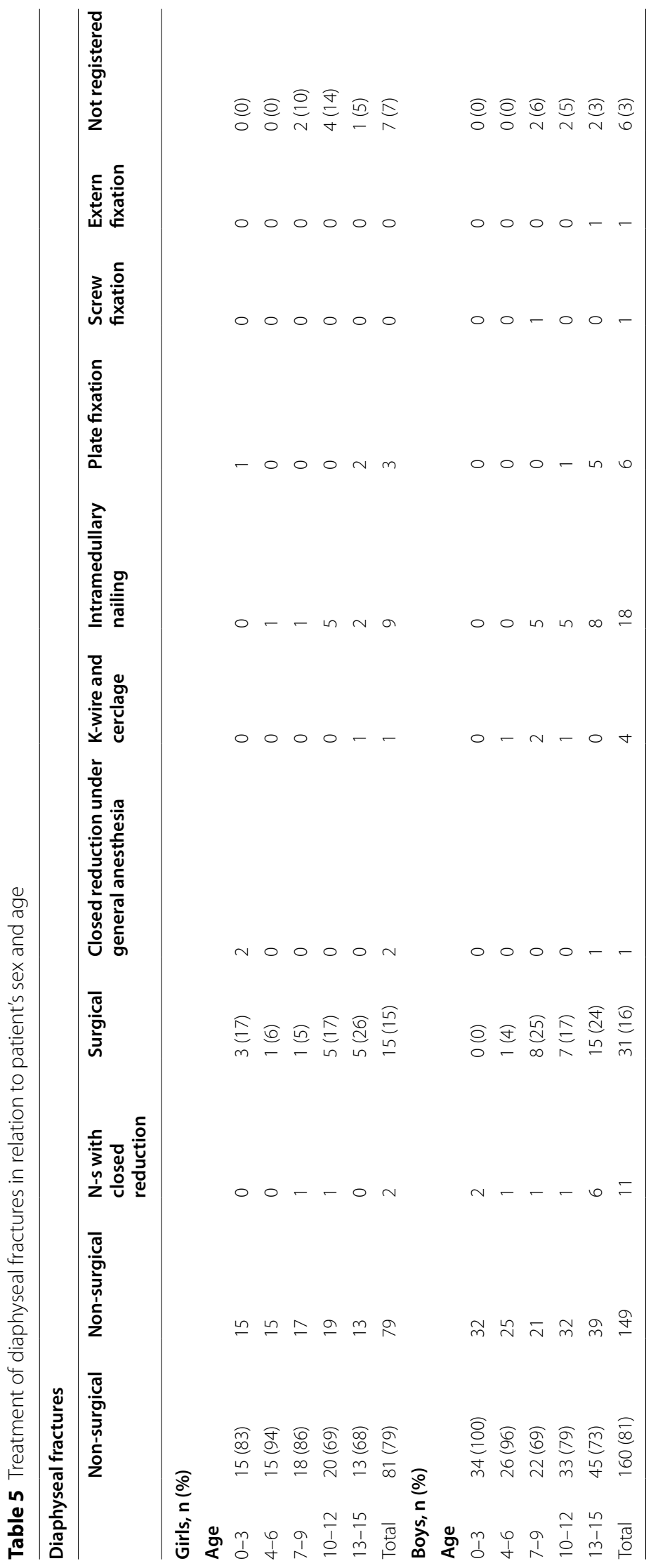


were treated surgically or had a fracture reduction. This reflecting our inclusion of both hospitalised and nonhospitalised patients.

Regarding the choice of surgical technique, there is an ongoing discussion on which surgical method should be used [25-28]. This varies both globally and in our study cohort. The diversity of surgical methods used indicates a more local tradition-based rather than evidence-based reason to choose one technique over the other. It might of course also reflect that the surgical technique chosen might - at least in children - not have such big impact on fracture healing since the reoperation rate is generally low. This also reflects the absence of randomised studies in children.

As hypothesised, we noted an increase in surgical treatment with increasing age. When considering surgery for the treatment of paediatric fractures, the child's bone age plays an important role: in young children most fractures can be treated non-surgically due to open growth plates and substantial remodelling capacity [24]. However, with increasing age the remodelling capacity is decreasing and surgical treatment is more often required to achieve alignment [13, 14]. Furthermore, fracture healing-time increases with age [29]. Older children would therefore need longer immobilisation periods. Considering the fact that girls reach puberty earlier than boys, we would have expected that age at surgery was younger in girls. This was the case in proximal humeral fractures but not in diaphyseal fractures. The choice of treatment, non-surgical or surgical was however not associated with sex.

\section{Strengths and limitations}

One notable strength of this study is the register design. The SFR is a nationwide register covering about $80 \%$ of Sweden's orthopedic units at our time of study, stretching from small countryside hospitals to university hospitals. Another notable strength are the very low numbers of incomplete data. Only a few percent of the registered fractures lacked information on injury mechanism, classification or treatment. The fractures were classified by the treating orthopaedic surgeon and previous validation studies have reported good accuracy in such classifications [30-32].

As with all register-based studies, a prominent limitation is the lack of completeness when comparing registered fractures with fractures registered in the NPR. However, the NPR-data are less suitable for an epidemiological study since they lack detailed information on injury site, injury mechanism and fracture classification. Another limitation with register-based studies is their vulnerability to misinterpretation of the variables when registering a fracture. The fact that some units only register paediatric fractures treated surgically, can cause selection bias and a false high frequency of surgical treated fractures. Outcomes in the SFR include registrations of reoperations which is out of the scope of this epidemiological study. Furthermore, reoperations need verification of medical records to be fully valid.

\section{Conclusions}

One in four paediatric humeral fractures occurred in the proximal or diaphyseal part. Girls were in majority in proximal fracturs and boys in diaphyseal fractures. Most children sustained their proximal and diaphyseal humeral fracture by falling from playground facilities, horseriding or winter sport activities. Further studies need to investigate if these fractures could be prevented with prophylactic efforts in activities. The surgical treatment increased with increasing age in in both sexes but the age at surgery was younger in girls with proximal humeral fractures. The surgical method showed a large variation of techniques and the registered re-operation rate was very low.

\section{Acknowledgements \\ Not applicable.}

\section{Authors' contributions}

$\mathrm{RM}, \mathrm{OW}$ and YDH designed the study, did the data collection and revised the manuscript. SDJ analysed the data and wrote the manuscript. All authors read and approved the final manuscript.

\section{Funding}

Open access funding provided by Uppsala University.

\section{Availability of data and materials}

The dataset analysed in this study is not publicly available as the study was approved on the ground of ensuring the confidentiality of data of patients included in the study. We are positive to sharing data but are legally restricted to share the data publicly according to the law on Public Access and Secrecy, chapter 21, paragraph 7 and chapter 25, paragraph 1 (https://www.riksdagen. se/sv/dokument-lagar/dokument/svensk-forfattningssamling/offentlighets\% 2D\%2Doch-sekretesslag-2009400_sfs-2009-400). Any person interested in the data set may contact Uppsala University and the corresponding author to find ways to share data according to Swedish laws and regulations. It is also possible for individuals interested in this data to apply directly from the Center of Registers, Västra Götaland (URL: http://registercentrum.se/). A process that involves an approval from the Swedish Ethical Review Authority.

\section{Declarations}

\section{Ethics approval and consent to participate}

The study was approved by the Swedish Ethical Review Authority (approval number 2019-04282, date of issue 10th of September 2019) and was performed in accordance with the Declaration of Helsinki. Informed consent was waived by Swedish Ethical Review Authority because of the register-based design of this study. The data we have used is manually registered in a specific national quality register separate from patients' medical records. Use of data is regulated by the Swedish patient data act, in the part that applies to national quality registers. In order to be registered in a quality register, it is required that the patient is informed and given the opportunity to opt out. The information must include that the data may be used for research after approval from a research ethical board. The research ethical board decides if consent is required or not, and if data should be anonymized. In our case the decision 
was made that no further information or consent is required, and that data must be anonymized.

\section{Consent for publication}

Not applicable.

\section{Competing interests}

The authors declare no competing interests in relation to the study.

Received: 26 May 2021 Accepted: 10 January 2022

Published online: 28 January 2022

\section{References}

1. Cooper C, Dennison EM, Leufkens HG, Bishop N, van Staa TP. Epidemiology of childhood fractures in Britain: a study using the general practice research database. J Bone Miner Res. 2004;19(12):1976-81.

2. Lempesis V, Rosengren BE, Nilsson J-Å, Landin L, Tiderius CJ, Karlsson MK. Time trends in pediatric fracture incidence in Sweden during the period 1950-2006. Acta Orthop. 2017;88(4):440-5.

3. Bergman $E$, Lempesis V, Nilsson J-Å, Jephsson L, Rosengren BE, Karlsson MK. Time trends in pediatric fractures in a Swedish city from 1950 to 2016. Acta Orthop. 2020:91(5):598-604.

4. Hedström EM, Svensson O, Bergström U, Michno P. Epidemiology of fractures in children and adolescents: increased incidence over the past decade: a population-based study from northern Sweden. Acta Orthop. 2010;81(1):148-53.

5. Shrader MW. Proximal Humerus and humeral shaft fractures in children. Hand Clin. 2007;23(4):431-5.

6. Kraus R, Wessel L. The treatment of upper limb fractures in children and adolescents. Dtsch Aerzteblatt online. 2010; Available from: https://www. aerzteblatt.de/10.3238/arztebl.2010.0903. Cited 2020 Feb 5

7. Mäyränpää MK, Mäkitie O, Kallio PE. Decreasing incidence and changing pattern of childhood fractures: a population-based study. J Bone Miner Res. 2010;25(12):2752-9.

8. Di Gennaro GL, Spina M, Lampasi M, Libri R, Donzelli O. Fractures of the proximal humerus in children. Chir Organi Mov. 2008;92(2):89-95.

9. Binder H, Tiefenboeck TM, Payr S, Schurz M, Aldrian S, Sarahrudi K. Treatment of proximal humerus fractures in children and young adolescents. Wien Klin Wochenschr. 2016;128(3-4):120-4.

10. Jenkins M, Nimphius S, Hart NH, Chivers P, Rantalainen T, Rueter K, et al. Appendicular fracture epidemiology of children and adolescents: a 10-year case review in Western Australia (2005 to 2015). Arch Osteoporos. 2018;13(1):63

11. Brudvik C, Hove LM. Childhood fractures in Bergen, Norway: identifying high-risk groups and activities. J Pediatr Orthop. 2003;23(5):629-34.

12. Hannonen J, Hyvönen H, Korhonen L, Serlo W, Sinikumpu J-J. The incidence and treatment trends of pediatric proximal humerus fractures. BMC Musculoskelet Disord. 2019;20(1):571.

13. Kelly DM. Flexible intramedullary nailing of pediatric humeral fractures: indications, techniques, and tips. J Pediatr Orthop. 2016;36:S49-55.

14. Dobbs MB, Luhmann SL, Gordon JE, Strecker WB, Schoenecker PL. Severely displaced proximal humeral epiphyseal fractures. J Pediatr Orthop. 2003;23(2):208-15.

15. Wennergren D, Ekholm C, Sandelin A, Möller M. The Swedish fracture register: 103,000 fractures registered. BMC Musculoskelet Disord. 2015;16(1):338.

16. Rennie L, Court-Brown CM, Mok JYQ, Beattie TF. The epidemiology of fractures in children. Injury. 2007;38(8):913-22.

17. Swedish Research Council for Sport Science. Föreningsidrott - barn och ungdomar: Swedish Research Council for Sport Science; 2019. Available from: https://idrottsstatistik.se/foreningsidrott/barn-och-ungdomar_/. Cited 2021 Apr 15

18. Faulkner RA, Davison KS, Bailey DA, Mirwald RL, Baxter-Jones AD. Size-corrected $B M D$ decreases during peak linear growth: implications for fracture incidence during adolescence. J Bone Miner Res. 2006;21(12):1864-70.

19. Salonen A, Pajulo O, Lahdes-Vasama T, Mattila VM. Stable incidence of surgical treatment and hospitalisation for humeral shaft fractures among 0- to 16-year-old patients in Finland from 1987 to 2010. J Child Orthop. 2014;8(2):143-8.
20. Bergdahl C, Ekholm C, Wennergren D, Nilsson F, Möller M. Epidemiology and patho-anatomical pattern of 2,011 humeral fractures: data from the Swedish fracture register. BMC Musculoskelet Disord. 2016;17(1):159.

21. Pierce MC, Bertocci GE, Vogeley E, Moreland MS. Evaluating long bone fractures in children: a biomechanical approach with illustrative cases. Child Abuse Negl. 2004;28(5):505-24.

22. Taskesen A, Göçer A, Uzel K, Yaradılmış YU. Effect of osteoporosis on proximal Humerus fractures. Geriatr Orthop Surg Rehabil. 2020;11:2151459320985399.

23. Ömeroğlu H. Basic principles of fracture treatment in children. Eklem Hast Ve Cerrahisi Jt Dis Relat Surg. 2018;29(1):52-7.

24. Gladden PB, Wilson CH, Suk M. Pediatric orthopedic trauma: principles of management. Semin Pediatr Surg. 2004;13(2):119-25.

25. Hutchinson PH, Bae DS, Waters PM. Intramedullary nailing versus percutaneous pin fixation of pediatric proximal Humerus fractures: a comparison of complications and early radiographic results. J Pediatr Orthop. 2011;31(6):617-22.

26. Chapman JR, Henley MB, Agel J, Benca PJ. Randomized prospective study of humeral shaft fracture fixation: intramedullary nails versus plates. J Orthop Trauma. 2000;14(3):162-6.

27. Canavese F, Marengo L, Cravino M, Giacometti V, Pereira B, Dimeglio A, et al. Outcome of conservative versus surgical treatment of humeral shaft fracture in children and adolescents: comparison between nonoperative treatment (Desault's bandage), external fixation and elastic stable intramedullary nailing. J Pediatr Orthop. 2017;37(3):e156-63.

28. Canavese F, Athlani L, Marengo L, Rousset M, Rouel-Rabiau N, Samba A, et al. Evaluation of upper-extremity function following surgical treatment of displaced proximal humerus fractures in children. J Pediatr Orthop B. 2014;23(2):144-9.

29. Clark D, Nakamura M, Miclau T, Marcucio R. Effects of aging on fracture healing. Curr Osteoporos Rep. 2017;15(6):601-8.

30. Wennergren D, Stjernström S, Möller M, Sundfeldt M, Ekholm C. Validity of humerus fracture classification in the Swedish fracture register. BMC Musculoskelet Disord. 2017;18(1):251.

31. Wennergren D, Ekholm C, Sundfeldt M, Karlsson J, Bhandari M, Möller M High reliability in classification of tibia fractures in the Swedish fracture register. Injury. 2016:47(2):478-82.

32. Juto $H$, Möller M, Wennergren D, Edin K, Apelqvist I, Morberg P. Substantial accuracy of fracture classification in the Swedish fracture register: evaluation of AO/OTA-classification in 152 ankle fractures. Injury. 2016;47(11):2579-83

\section{Publisher's Note}

Springer Nature remains neutral with regard to jurisdictional claims in published maps and institutional affiliations.

Ready to submit your research? Choose BMC and benefit from

- fast, convenient online submission

- thorough peer review by experienced researchers in your field

- rapid publication on acceptance

- support for research data, including large and complex data types

- gold Open Access which fosters wider collaboration and increased citations

- maximum visibility for your research: over $100 \mathrm{M}$ website views per year

At BMC, research is always in progress.

Learn more biomedcentral.com/submissions 